TITLE:

\title{
Temporal variation in modal properties of a base-isolated building during an earthquake
}

\author{
$\operatorname{AUTHOR}(\mathrm{S})$ : \\ Takewaki, Izuru; Takewaki, Mitsuru
}

\section{CITATION:}

Takewaki, Izuru ...[et al]. Temporal variation in modal properties of a base-isolated building during an earthquake. Journal of Zhejiang University - Science A 2010, 11(1): 1-8

\section{ISSUE DATE:}

2010-01

URL:

http://hdl.handle.net/2433/89633

\section{RIGHT:}

c Springer. Springer Science+Business Media.; This is not the published version. Please cite only the published version.; この論文は出版社版で ありません。引用の際には出版社版をご確認ご利用ください。 


\title{
Temporal variation of modal properties of a base-isolated building during an earthquake
}

\author{
Izuru TAKEWAKI*1 and Mitsuru NAKAMURA** \\ *Department of Urban and Environmental Engineering, Graduate School of Engineering, \\ Kyoto University, Sakyo, Kyoto 606-8501, Japan \\ **Technical Research Institute, Obayashi Corporation, Kiyose, Tokyo 204-8558, Japan
}

\begin{abstract}
Temporal variation of dynamical modal properties of a base-isolated building is investigated using earthquake records in the building. A batch processing least-squares estimation method is applied to segment-wise time-series data. To construct an input-output system, an ARX model of second-order including a forgetting coefficient as a weighting coefficient is used for the estimation of modal parameters. The fundamental and second natural frequencies and the damping ratios of the fundamental and second natural modes of the base-isolated building are identified in the time domain. It is shown that the identified results are consistent with the results obtained from the micro-tremor vibration data, forcedvibration test data and earthquake records in the present base-isolated building in the case of taking into account the amplitude-dependency of the isolators and viscous dampers. It is pointed out finally that several factors, e.g. amplitude dependency of the isolator and damper system and special characteristics of the series-type viscous damper system, may be related complicatedly with the temporal variation of the above-mentioned system modal properties.
\end{abstract}

Key words: system identification, shear building model, modal parameters, batch processing least-squares estimation method, forgetting coefficient, ARX model

\footnotetext{
${ }^{1}$ Corresponding author, e-mail: takewaki@archi.kyoto-u. ac.jp
} 


\section{INTRODUCTION}

There are many base-isolated buildings in Japan after Hyogoken-Nambu earthquake (1995). However, it does not seem that the instrumentation of earthquake records at those base-isolated buildings is sufficient enough to demonstrate the validity and reliability of the design methods for base-isolated buildings. For this reason, a detailed instrumentation of earthquake records has been implemented by the present authors in Kyoto University since 1997.

System identification (SI) techniques have a long history and have played important roles in identifying gaps between the constructed structural systems and their design models and in health monitoring for damage detection (Hart and Yao 1977; Beck and Jennings 1980; Hoshiya and Saito 1984; Agbabian et al. 1991; Koh et al. 1991; Yao and Natke 1994; Ghanem and Shinozuka 1995; Hjelmstad et al. 1995; Shinozuka and Ghanem 1995; Doebling et al. 1996; Hjelmstad 1996; Masri et al. 1996; Housner et al. 1997; Herrmann and Prandlwarter 1998; Kitada 1998). A great amount of researches have been performed so far in SI. Modal-parameter SI and physical-parameter SI are two major branches in SI (Hart and Yao 1977). The former is believed to be appropriate for identifying the overall mechanical properties of a structural system and exhibits stable characteristics in implementation. While the latter is regarded to be important from different viewpoints, e.g. enhancement of reliability in active controlled structures (Housner et al. 1997) or baseisolated structures, its development is limited because of the requirement of multiple measurements or the necessity of complicated manipulation. A mixed approach is often used in which physical parameters are identified from the modal parameters obtained by the modal-parameter SI. However, a sufficient number of modal parameters must be obtained for the unique and accurate identification of the physical parameters. This requirement can not be satisfied in most cases.

Although the importance of damping in the seismic-resistant design of buildings is well recognized (Hart and Vasudevan 1975), it does not appear that its identification techniques have been developed sufficiently. Especially the identification techniques for physical parameters, i.e. viscous damping coefficients and material damping ratios, are not fully 
developed compared to those for modal damping (Davenport and Hill-Carroll 1986; Kareem and Gurley 1996; Lus et al. 1999; Stewart et al. 1999; Satake et al. 2003). To overcome this difficulty, the present authors developed some useful physical-parameter system identification methods (Takewaki and Nakamura 2000, 2005, Yoshitomi and Takewaki 2009).

In this paper, temporal variation of modal properties of a base-isolated building is investigated using earthquake records in the building. An ARX model of second-order including a forgetting coefficient as a weighting coefficient is used for estimation of the modal parameters of the system. The fundamental and second natural frequencies and the damping ratios of the fundamental and second natural modes are identified in the time domain. It will be pointed out that several factors, e.g. amplitude dependency of the isolator and damper system and special characteristics of the series-type viscous damper system, may be related with the temporal variation of the above-mentioned system modal properties. It will also be shown that the micro-tremor vibration data, forced-vibration test data and earthquake records in the present base-isolated building provide consistent results on amplitudedependency of the isolators and viscous dampers.

\section{SYSTEM IDENTIFICATION METHOD}

A batch processing least-squares estimation method (for example see Mendel 1995) is applied to segment-wise time-series data. It is assumed that the base-isolated building treated in this paper can be described by an ARX model expressed by

$$
A(q) y(k)=B(q) u(k)+w(k)
$$

$u(k)$ and $y(k)$ in Eq.(1) are the input and output sequences and $w(k)$ is a white noise signal. $A(q)$ and $B(q)$ are the polynomials including the AR and MA coefficients $\left\{a_{i}\right\},\left\{b_{i}\right\}$ and are defined by

$$
\begin{aligned}
& A(q)=1+a_{1} q^{-1}+\cdots+a_{n_{a}} q^{-n_{a}} \\
& B(q)=b_{1} q^{-1}+\cdots+b_{n_{b}} q^{-n_{b}}
\end{aligned}
$$


In Eqs.(2a, b), $q^{-j}$ is the back-ward shift operator and is defined by $q^{-j} y(k)=y(k-j)$. Furthermore $n_{a}$ and $n_{b}$ are the orders of the output and input of the system.

The AR and MA coefficients $\left\{a_{i}\right\},\left\{b_{i}\right\}$ in Eq.(2a, b) can be evaluated by using the input and output sequences $u(k)$ and $y(k)$ recorded in the actual building. The scheme of determination of these coefficients will be explained in the following.

The model parameters are assumed to be estimated by the following equation.

$$
\theta(N)=R(N)^{-1} f(N)
$$

where $\theta(N), R(N)$ and $f(N)$ can be defined by

$$
\begin{aligned}
& \theta(N)=\left[a_{1}, a_{2}, \ldots, a_{n_{a}}, b_{1}, b_{2}, \ldots b_{n_{b}}\right]^{T} \\
& R(N)=\frac{1}{N} \sum_{k=1}^{N} \lambda^{N-k} \varphi(k) \varphi^{T}(k) \\
& f(N)=\frac{1}{N} \sum_{k=1}^{N} \lambda^{N-k} y(k) \varphi(k)
\end{aligned}
$$

In Eqs.(4b, c), $\lambda$ expresses a forgetting coefficient for the better representation of stochastic parameter estimate and $\varphi(k)$ is given by

$$
\varphi(k)=\left[-y(k-1), \ldots-y\left(k-n_{a}\right), u(k-1), \ldots, u\left(k-n_{b}\right)\right]^{T}
$$

For this ARX model, the natural frequencies $f_{j}$ and damping ratios $\xi_{j}$ are evaluated as the modulus $p_{j}$ and the arguments $\xi_{j}$ of the poles of the polynomial equation including the AR and MA coefficients by (Safak 1989)

$$
f_{j}=\frac{-\ln \left|p_{j}\right|}{2 \pi \xi_{j} d t}
$$




$$
\xi_{j}=\frac{-\ln \left|p_{j}\right|}{\left[\arg ^{2}\left(p_{j}\right)+\left\{\ln \left|p_{j}\right|\right\}^{2}\right]^{1 / 2}}
$$

where $d t$ is the sampling interval.

Fig. 1 shows the conceptual diagram of the system identification method used in this paper. A time segment of $5(\mathrm{sec})$ will be moved sequentially for enabling the temporal identification of modal parameters.

Based on the previous investigations (Takewaki and Nakamura 2000, 2005), the fundamental dynamical properties of this base-isolated building have been made clear to some extent. Analysis of recorded motions by a band-pass filter around the natural frequencies enabled one to determine the order of the ARX model as the second order.

The above procedure has been implemented for each time segment and system identification has been conducted for the fundamental and second natural frequencies and the damping ratios of the fundamental and second natural modes.

\section{OBSERVATION OF EARTHQUAKE RECORDS IN BASE-ISOLATED BUILDING}

The observation of earthquake motions has been made in a base-isolated building at the Yoshida Campus of Kyoto University (Nakamura et al. 1998, Nakamura and Takewaki 2002, 2005, Takewaki and Nakamura 2000, 2005). The overview of the building and accelerometer locations are shown in Fig.2. This building is a three-story reinforced concrete building with basement and the base-isolation system is installed under the basement. The base-isolation system consists of 17 natural rubber bearings and 14 viscous dampers. The viscous damper system includes a viscous damper with butanoic-oil for earthquake motions and a viscous damper with silicon-oil for small vibrations in series. Several earthquake records are utilized here (see Table 1).

Fig.3 shows the relations of the fundamental natural period (upper one) and the lowestmode damping ratio (lower one) with the deformation amplitude in the base-isolation story (Nakamura et al. 1998). The horizontal axis is the maximum deformation amplitude in the base-isolation story. The micro-tremor vibration data, forced-vibration test data and the 
results obtained from earthquake records are plotted in Fig.3. It can be observed that the fundamental natural period in EW direction is longer than that in NS direction and the fundamental natural period becomes longer for larger deformation amplitudes. It seems that this results from the amplitude-dependency of the isolator horizontal stiffness. It is also found that the damping ratio becomes larger for larger deformation amplitudes. However it should be noted that the amplitude-dependency of the damping ratio includes the effect of the amplitude-dependency of the natural period.

Fig.4 illustrates the relation of the damping coefficient of the viscous damper installed in the base-isolation story with the deformation amplitude in the base-isolation story. This figure has been obtained from the relation (damping coefficient)=2*(lowest-mode damping ratio)*(fundamental natural circular frequency)*(total mass of building). The fundamental natural circular frequency and the lowest-mode damping ratio have been used in this analysis. The forced-vibration test data and the results obtained from earthquake records are compatible with the results by the viscous damper test.

\section{RESULT OF MODAL-PARAMETER SYSTEM IDENTIFICATION}

The records at the base-isolation story and the second floor have been used because it is known from the previous investigation that the effect or component of the second vibration mode is small in the second floor. Fig.5 shows the vibration-mode shapes of the fundamental and second natural modes obtained from the forced vibration test. For the identification of the second mode, on the other hand, the records at the base-isolation story and the BF1 are used.

Fig.6 illustrates the acceleration records at the levels of 2F, BF1, BI floor (Tokaido-oki Earthquake 2004.9.5 NS). It can be observed that the acceleration can be reduced remarkably in the building. Fig.7 indicates the temporal variation of the interstory drift in the base-isolation story. This figure has been drawn to make clear the relation of modal properties with the amplitude of vibration. Fig.8 shows the temporal variation of fundamental and second natural frequencies (Tokaido-oki Earthquake 2004.9.5 NS). It is understood that the fundamental natural frequency at the initial stage corresponds fairly well 
with the value $(0.62-0.65 \mathrm{~Hz})$ obtained from the micro-tremor observation shown in Fig. 3 and becomes smaller in the beginning of the earthquake records (10s-40s). After 40s, the fundamental natural frequency remains a reduced value. Similarly the second natural frequency corresponds fairly well with the value $(7.0 \mathrm{~Hz})$ obtained from the micro-tremor observation. However, the reduction of the second natural frequency is not clear compared with the fundamental natural frequency. Fig.9 illustrates the temporal variation of damping ratios of fundamental and second natural modes (Tokaido-oki Earthquake 2004.9.5 NS). It can be found that the initial damping ratio in the fundamental mode corresponds fairly well with the value (0.08) obtained from the micro-tremor observation shown in Fig. 3. After the damping ratio in the fundamental mode becomes larger a little bit, it reduces as the interstory drift in the base-isolation story becomes larger. It can be supposed that the amplitude dependency of the isolator and damper system and special characteristics of the series-type viscous damper system give an influence on the temporal variation of the system modal properties.

The corresponding figures for EW component are shown in Figs.10-13. A similar tendency can be observed also in EW components. The fundamental natural frequency at the initial stage corresponds fairly well with the value $(0.51 \mathrm{~Hz})$ obtained from the microtremor observation shown in Fig. 3 and becomes smaller in the beginning of the earthquake records (10s-50s). The initial damping ratio in the fundamental mode also corresponds fairly well with the value (0.09) obtained from the micro-tremor observation shown in Fig. 3. After the damping ratio in the fundamental mode becomes larger, it reduces as the interstory drift in the base-isolation story becomes larger (after 60s). Similarly the second natural frequency corresponds fairly well with the value $(5.9 \mathrm{~Hz})$ obtained from the micro-tremor observation. However, the reduction of the second natural frequency is not clear compared with the fundamental natural frequency.

Fig.14 illustrates the velocity response spectra of the earthquake records (Tokaido-oki Earthquake 2004.9.5) at the base center. It can be seen that a long-period motion (around 10s) exists in these earthquake records together with the motion around 1s. 
To investigate the effect of the type of earthquakes on the reliability of the present identification method, other earthquakes (Tottoriken-Seibu 2000 NS and South of Kyoto Prefecture 2001 NS) have been used. Fig.15 shows the time variations of the interstory drift in the base-isolation story, the fundamental natural frequency and the lowest-mode damping ratio for Tottoriken-Seibu 2000 NS and Fig.16 illustrates those for South of Kyoto Prefecture 2001 NS. It can be observed that the properties similar to the results for the abovementioned earthquake records can be found.

It may be possible to conclude that several factors, e.g. the amplitude dependency of the isolator and damper system and special characteristics of the series-type viscous damper system, are related closely with the temporal variation of the system modal properties (natural frequencies and modal damping ratios.

\section{CONCLUSIONS}

Dynamic properties of a base-isolated building have been investigated using observed field data. The following observations have been obtained.

(1) The combination of a batch processing least-squares estimation method and the ARX model representation of the input-output system is an efficient and reliable method of system identification of base-isolated buildings.

(2) The fundamental natural frequency and the damping ratio of the base-isolated building are time-dependent. This time-dependency is not a simple amplitude-dependent one, but seems to depend on the properties of earthquake ground motions and on the damping system used in this base-isolated building.

(3) The micro-tremor vibration data, forced-vibration test data and earthquake records in the present base-isolated building provide consistent results on amplitude-dependency of the isolators and viscous dampers.

\section{Acknowledgments}

The present work is partially supported by the Collaboration Project between Kyoto University and Obayashi Corporation (1998-2002). The authors are grateful to Professors K. 
Uetani of Kyoto University and Y. Yasui of Fukui Institute of Technology (formerly Obayashi Corporation) for their supports. This work is also partially supported by the Grant-in-Aid for Scientific Research (No.10650562) from the Ministry of Education, Science, Sports and Culture of Japan and by the Grant-in-Aid for Scientific Research (No.16560496) from the Japan Society for the Promotion of Science.

\section{References}

Agbabian, M.S., Masri, S.F., Miller, R.K., and Caughey, T.K. (1991) 'System identification approach to detection of structural changes', J. Engng. Mech., ASCE, 117(2), 370-390.

Beck, J.L., and Jennings, P.C. (1980) 'Structural identification using linear models and earthquake records', Earthquake Engng. Struct. Dyn., 8, 145-160.

Davenport, A.G., and Hill-Carroll, P. (1986) 'Damping in tall buildings: Its variability and treatment in design', Proc. ASCE Spring Convention, Seattle, ASCE, 42-57.

Doebling, S.W., Farrar, C.R., Prime, M.B., and Shevitz, D.W. (1996) 'Damage identification and health monitoring of structural and mechanical systems from changes in their vibration characteristics: A literature review', Los Alamos National Laboratory Report LA-13070-MS.

Ghanem, R., and Shinozuka, M. (1995) 'Structural-system identification I: Theory', J. Engng. Mech., ASCE, 121(2), 255-264.

Hart, G.C., and Vasudevan, R. (1975) 'Earthquake design of buildings: Damping', J. Struct. Div., ASCE, 101(ST1), 11-30.

Hart, G.C., and Yao, J.T.P. (1977) 'System identification in structural dynamics', J. Engng. Mech. Div., ASCE, 103(EM6), 1089-1104.

Herrmann, T., and Pradlwarter, H.J. (1998) 'Two-step identification approach for damped finite element models', J. Engng. Mech., ASCE, 124(6), 639-647.

Hjelmstad, K.D. (1996) 'On the uniqueness of modal parameter estimation', J. Sound and Vib., 192(2), 581-598.

Hjelmstad, K.D., Banan, Mo.R., and Banan, Ma.R. (1995) 'On building finite element models of structures from modal response', Earthquake Engng. Struct. Dyn., 24, 53-67. 
Hoshiya, M., and Saito, E. (1984) 'Structural identification by extended Kalman filter', J. Engng. Mech., ASCE, 110(12), 1757-1770.

Housner, G., et al. (1997) 'Special issue, Structural control : past, present, and future', J. Engng. Mech., ASCE, 123(9), 897-971.

Inaudi, J.A., and Kelly, J.M. (1995) 'Linear hysteretic damping and the Hilbert transform', J. Engng. Mech., ASCE, 121(5), 626-632.

Kareem, A., and Gurley, K. (1996) 'Damping in structures: Its evaluation and treatment of uncertainty', J. Wind Engng. Ind. Aerodyn., 59, 131-157.

Koh, C.G., See, L.M., and Balendra, T. (1991) 'Estimation of structural parameters in time domain: a substructure approach', Earthquake Engng. Struct. Dyn., 20, 787-801.

Lus, H., Betti, R., and Longman, R.W. (1999) 'Identification of linear structural systems using earthquake-induced vibration data', Earthquake Engng. Struct. Dyn., 28, 1449-1467.

Masri, S.F., Nakamura, M., Chassiakos, A.G., and Caughey, T.K. (1996) 'A neural network approach to the detection of changes in structural parameters', J. Engng. Mech., ASCE, 122(4), 350-360.

Mendel, J.M. (1995), Lessons in Estimation Theory for Signal Processing, Communications, and Control, 2nd Edition, Prentice Hall.

Nakamura, M., Takewaki, I., Yasui, Y., and Uetani, K. (1998) 'System identification method for interstory stiffness and damping through limited observation: Application to ambient vibration and robustness for noise', Summaries of annual meeting of AIJ, Structure II, 291-292 (in Japanese).

Nakamura, M., and Takewaki, I. (2002) 'System identification method for interstory stiffness and damping through limited observation: Application to ambient vibration and robustness for noise', Summaries of annual meeting of AIJ, Structure II, 291-292 (in Japanese).

Nakamura, M., and Takewaki, I. (2005) 'Evaluation of time-variance of dynamic properties of a base-isolated building during an earthquake', Summaries of annual meeting of AIJ, Structure II, 675-676 (in Japanese). 
Nashif, A.D., Jones, D.I.G., and Henderson, J.P. (1985) Vibration Damping, John Wiley \& Sons.

Safak, E. (1989) 'Adaptive modeling, identification, and control of dynamic structural systems I: Theory', J. Engng. Mech., ASCE, 115(11), 2386-2405.

Satake, N., Suda, K., Arakawa, T., Sasaki, A, and Tamura, Y. (2003) 'Damping evaluation using full-scale data of buildings in Japan', J. Struct. Engng., ASCE, 129(4), 470-477.

Shinozuka, M., and Ghanem, R. (1995) 'Structural-system identification II: Experimental verification', J. Engng. Mech., ASCE, 121(2), 265-273.

Stewart, J.P., Conte, J.P., and Aiken, I.D. (1999) 'Observed behavior of seismically isolated buildings', J. Struct. Engng., ASCE, 125(9), 955-964.

Takewaki, I., and Nakamura, M. (2000) 'Stiffness-damping simultaneous identification using limited earthquake records', Earthquake Engineering and Structural Dynamics, 29(8), 1219-1238.

Takewaki, I., and Nakamura, M. (2005). 'Stiffness-damping simultaneous identification under limited observation', Journal of Engineering Mechanics, ASCE, 131(10), 1027-1035.

Yao, J.T.P., and Natke, H.G. (1994) 'Damage detection and reliability evaluation of existing structures', Structural Safety, 15, 3-16.

Yoshitomi, S., and Takewaki, I. (2009). 'Noise-effect compensation method for physicalparameter system identification under stationary random input', Structural Control and Health Monitoring, 16(3), 350-373.

Table 1 Earthquake data and maximum accelerations just above and below base-isolation story

\begin{tabular}{|c|l|c|c|c|c|c|c|c|}
\hline \multicolumn{4}{|c|}{ Earthquake data } & \multicolumn{3}{c|}{ maximum acceleration (gal) } \\
\hline \multicolumn{1}{|c|}{ date } & \multicolumn{1}{|c|}{ epicenter } & depth & magnitude & $\begin{array}{c}\text { earthquake } \\
\text { intensity }\end{array}$ & base NS & base EW & $\begin{array}{c}\text { B1F } \\
\text { NS }\end{array}$ & $\begin{array}{c}\text { B1F } \\
\text { EW }\end{array}$ \\
\hline 1997.3 .16 & East of Aichi Pref. & $39 \mathrm{~km}$ & 5.8 & 2 & 8.09 & 3.45 & 2.24 & 4.38 \\
\hline 1997.6 .12 & Southeast of Hyogo Pref. & $20 \mathrm{~km}$ & 3.9 & 1 & 2.78 & 3.16 & 3.18 & 1.66 \\
\hline 1997.6 .25 & West of Shimane Pref. & $12 \mathrm{~km}$ & 6.1 & 0 & 1.00 & 0.84 & 1.26 & 0.51 \\
\hline 1997.9 .7 & South of Kyoto Pref. & $17 \mathrm{~km}$ & 4.2 & 2 & 4.69 & 10.61 & 5.87 & 6.97 \\
\hline 1998.2 .6 & South of Kyoto Pref. & $10 \mathrm{~km}$ & 3.8 & 0 & 1.98 & 1.78 & 1.74 & 2.46 \\
\hline 1998.2 .10 & Hida District of Gifu Pref. & $10 \mathrm{~km}$ & 4.3 & 1 & 1.71 & 1.52 & 0.49 & 0.97 \\
\hline
\end{tabular}




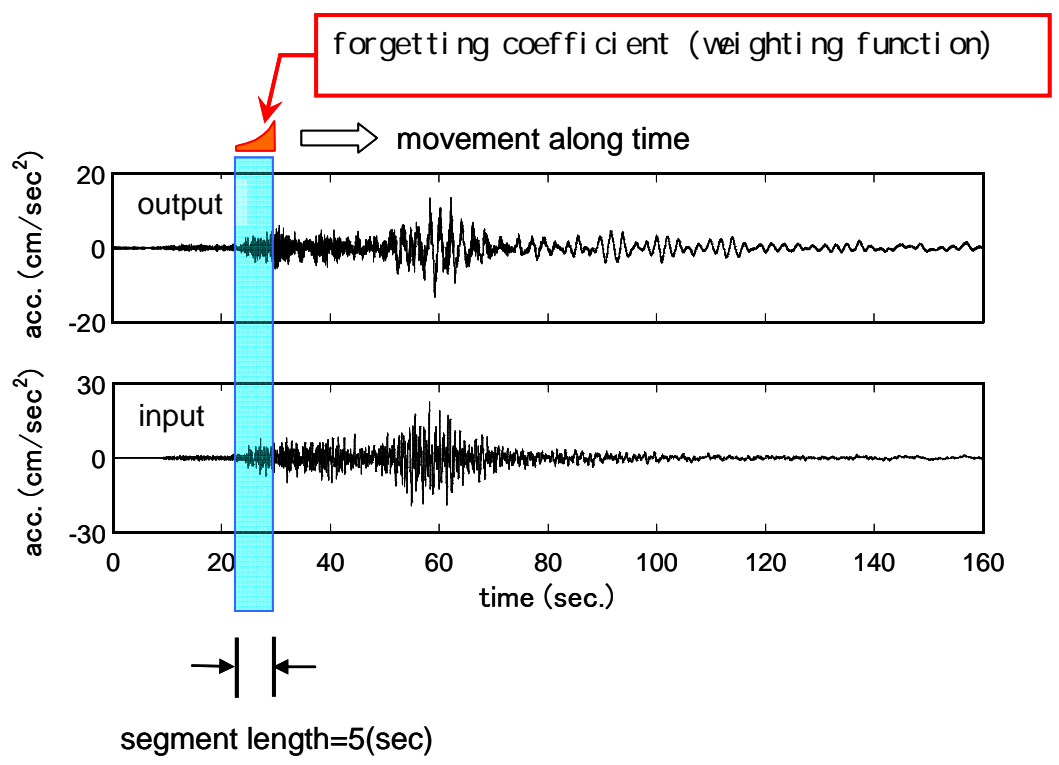

Fig.1 Conceptual diagram of the system identification used in this paper
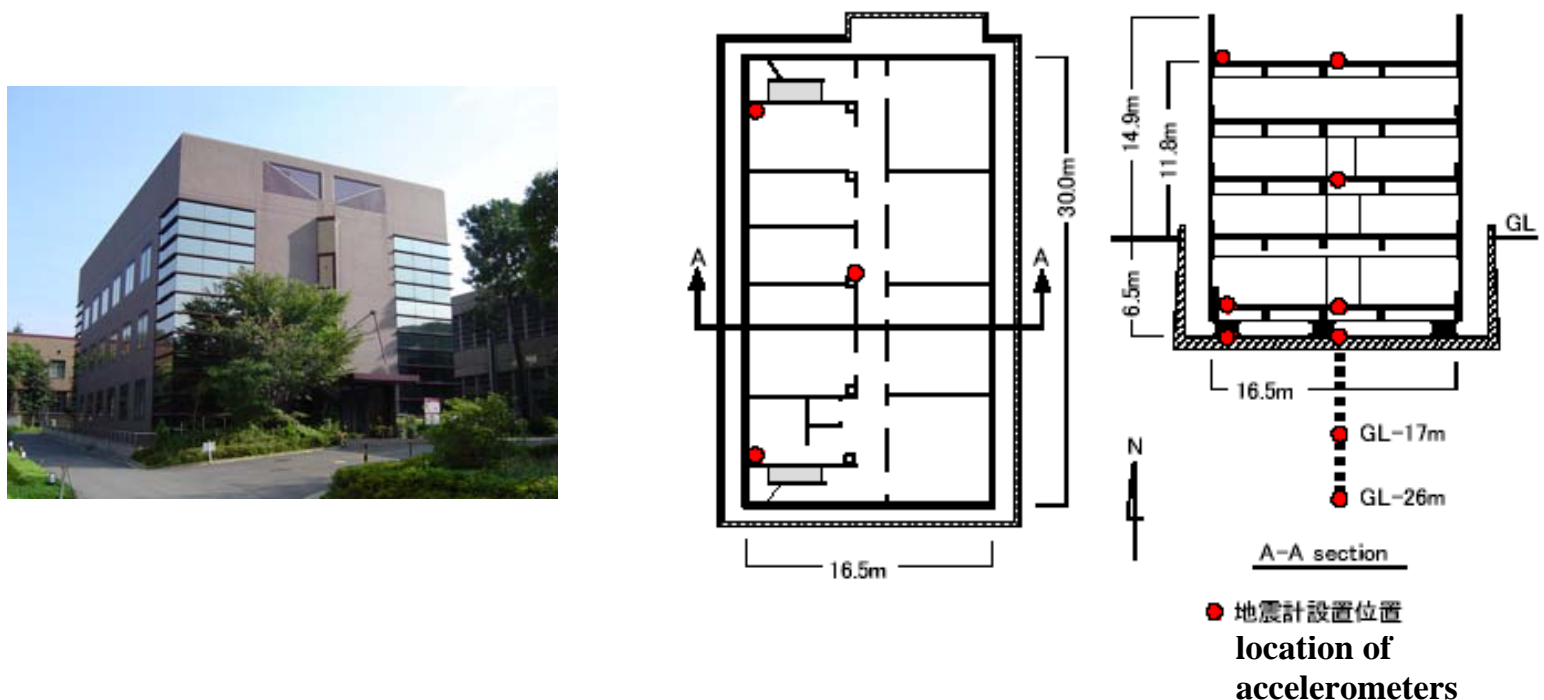

Fig.2 Overview of the base-isolated building and accelerometer location at the Kyoto University campus 


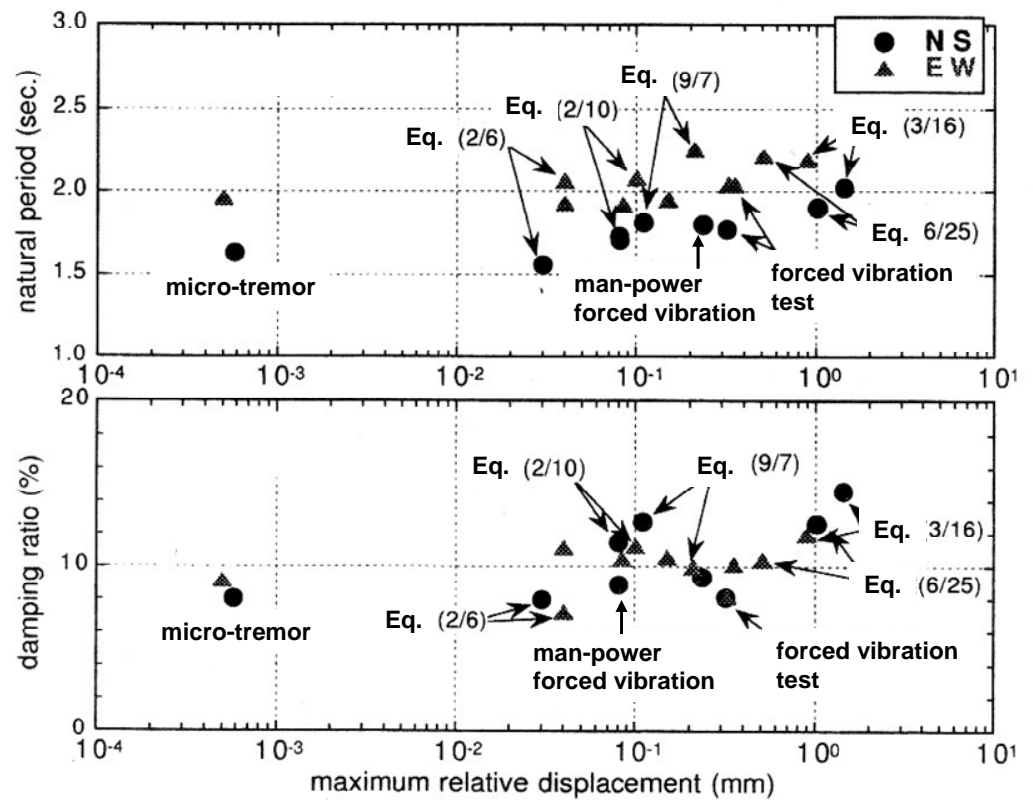

Fig.3 Relations of the fundamental natural period and the lowest-mode damping ratio with the deformation amplitude in the base-isolation story

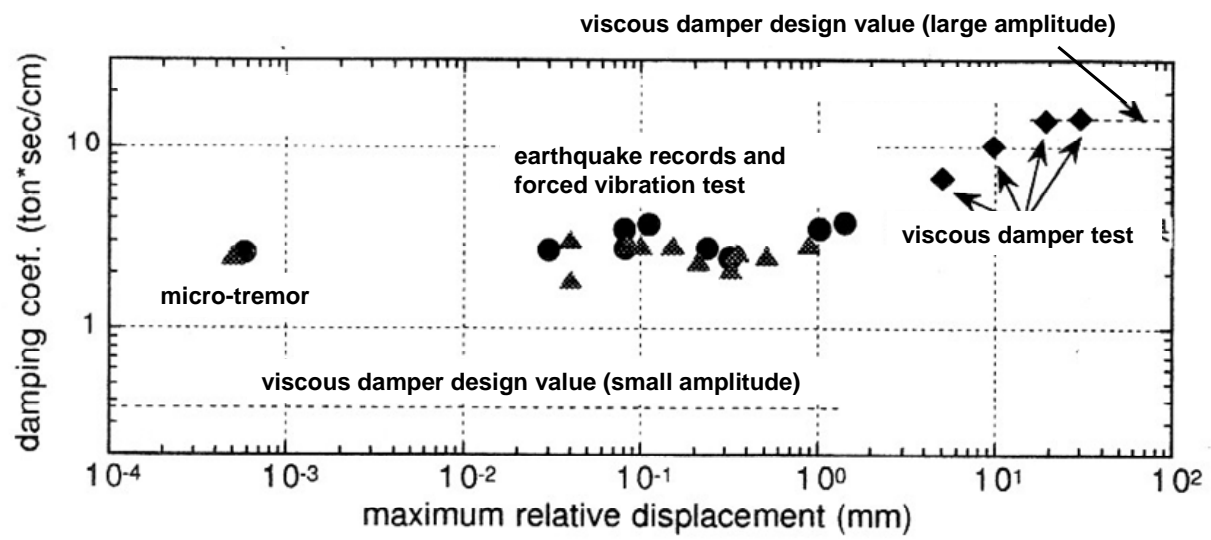

Fig.4 Relation of the damping coefficient of the viscous damper installed in the base-isolation story with the deformation amplitude in the base-isolation story 


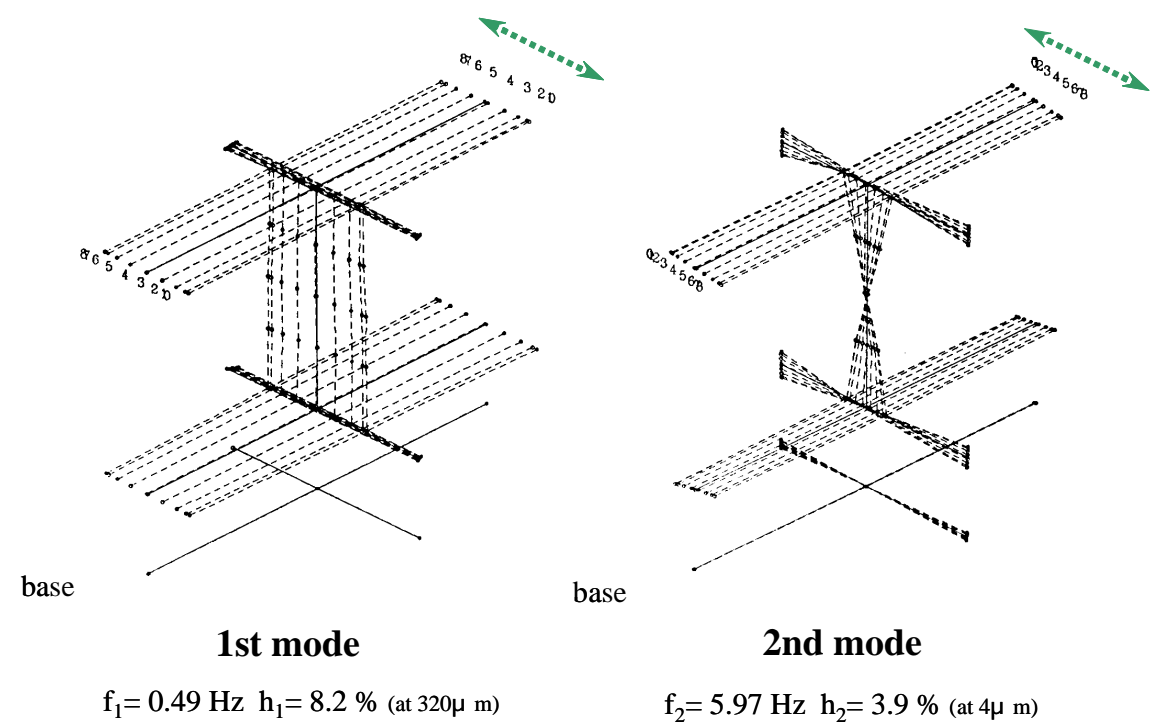

Fig.5 Vibration-mode shapes of the fundamental and second natural modes obtained from the forced vibration test 

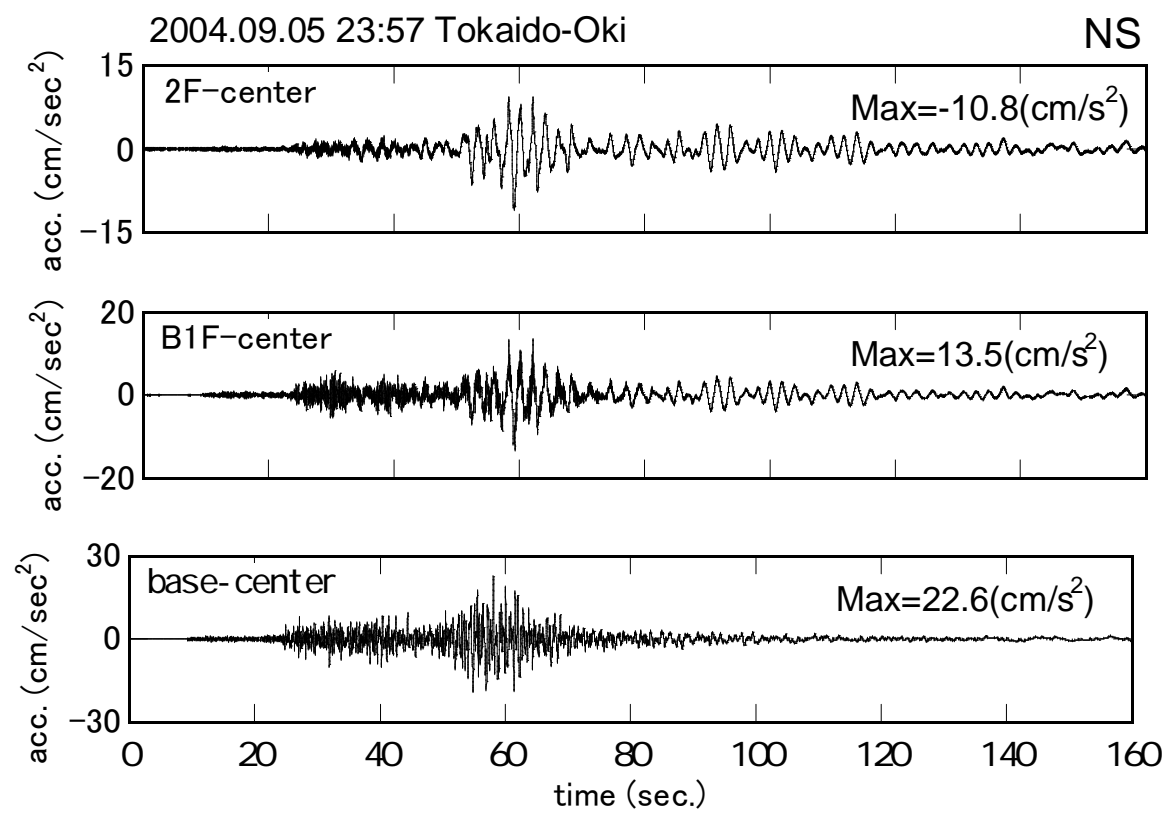

Fig.6 Acceleration records at the levels of 2F, BF1, BI floor

(Tokaido-oki Earthquake 2004.9.5 NS)

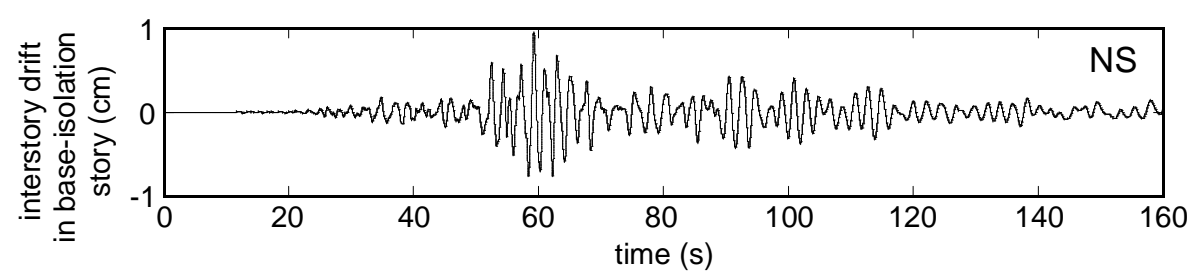

Fig.7 Interstory drift in the base-isolation story (Tokaido-oki Earthquake 2004.9.5 NS)
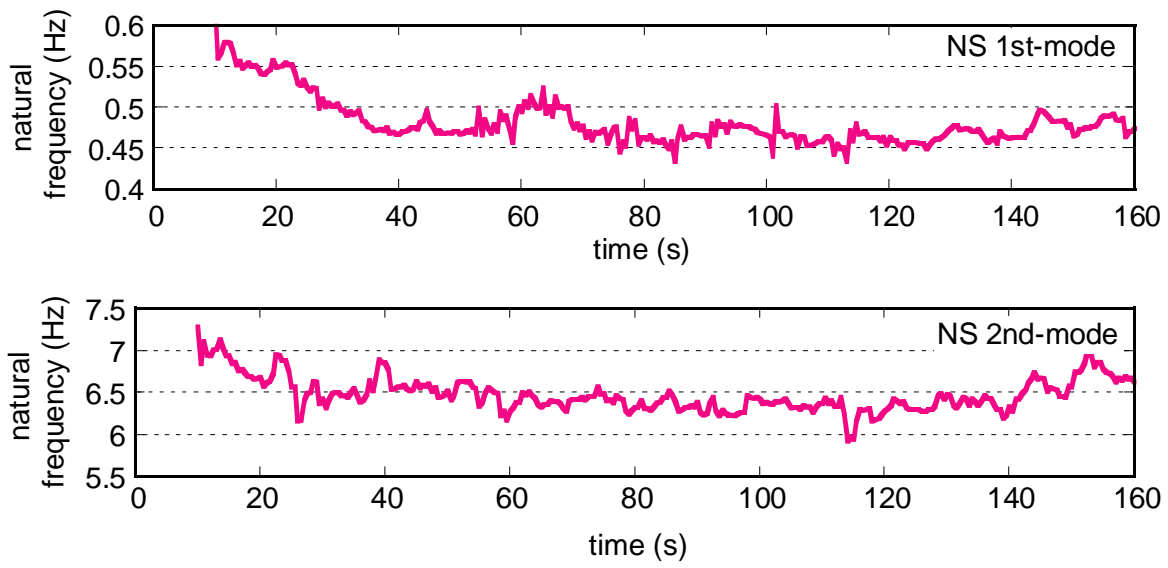

Fig.8 Temporal variation of fundamental and second natural frequencies

(Tokaido-oki Earthquake 2004.9.5 NS) 

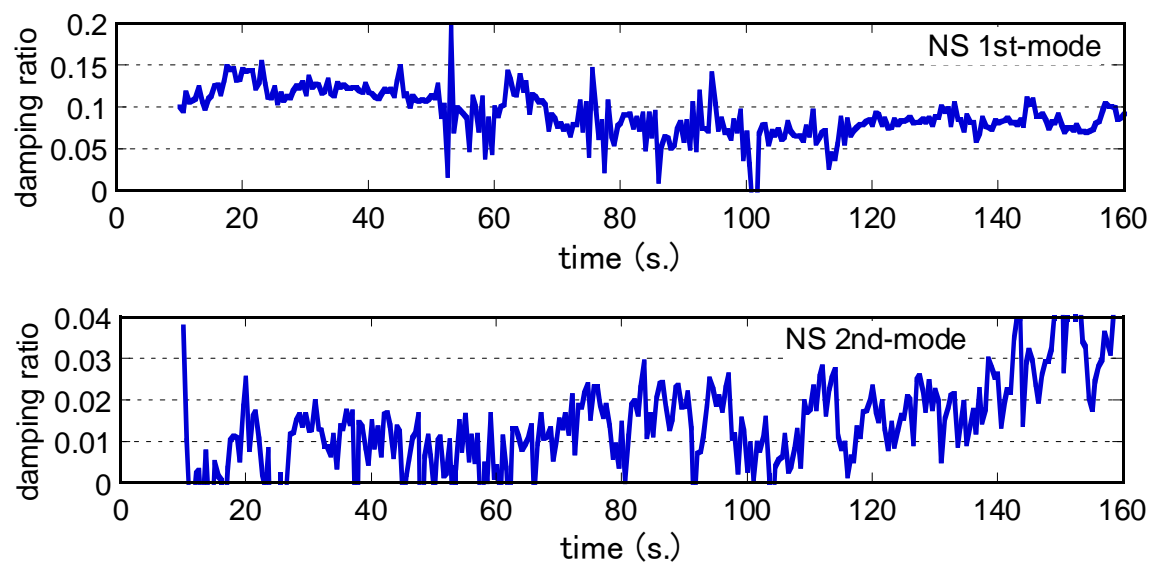

Fig.9 Temporal variation of damping ratios of fundamental and second natural modes (Tokaido-oki Earthquake 2004.9.5 NS)
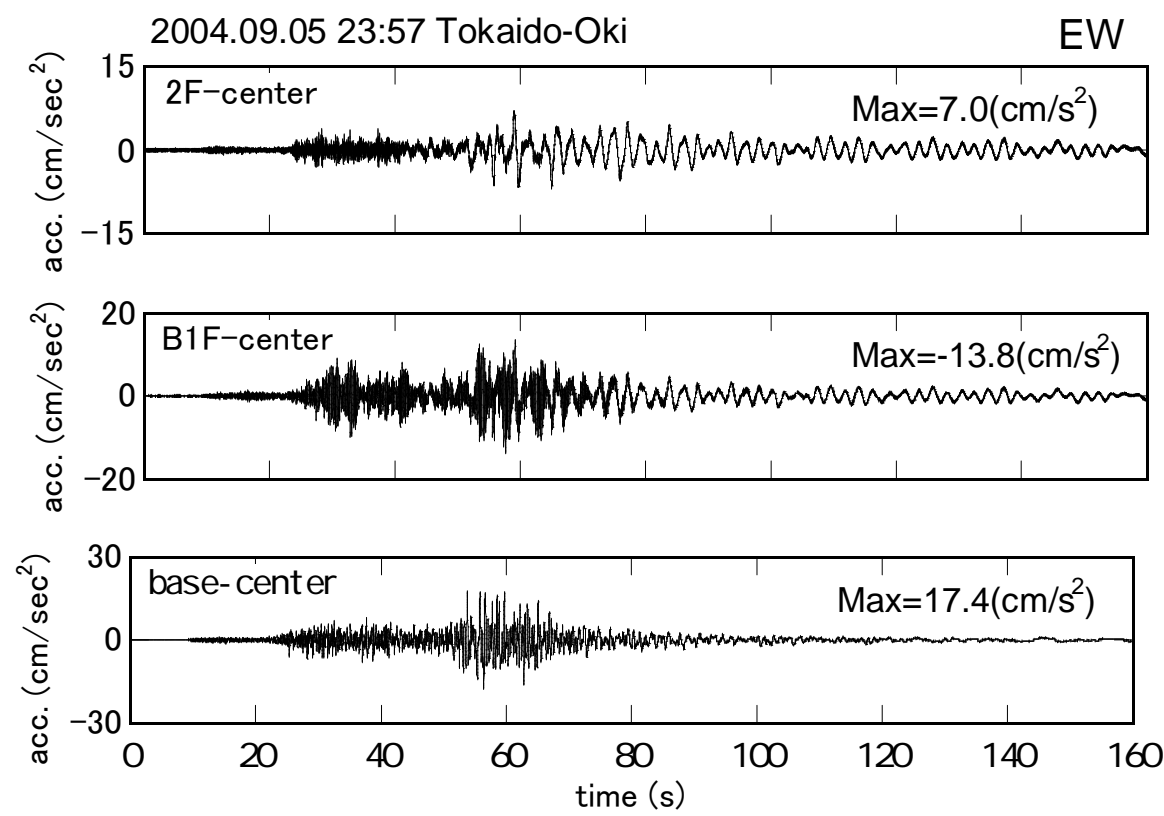

Fig.10 Acceleration records at the levels of 2F, BF1, BI floor (Tokaido-oki Earthquake 2004.9.5 EW)

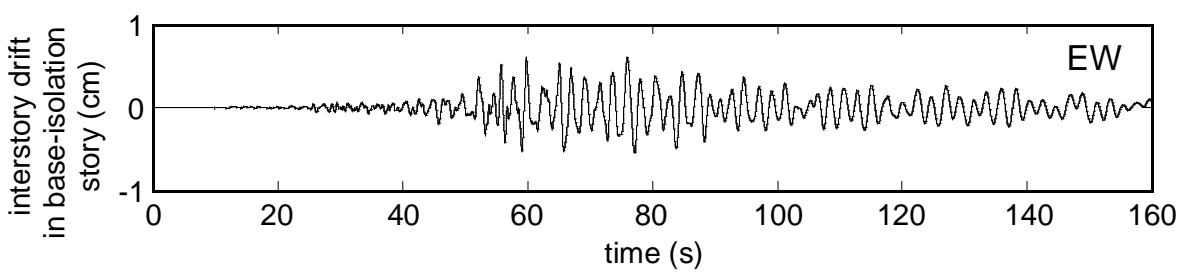

Fig.11 Interstory drift in the base-isolation story (Tokaido-oki Earthquake 2004.9.5 EW) 

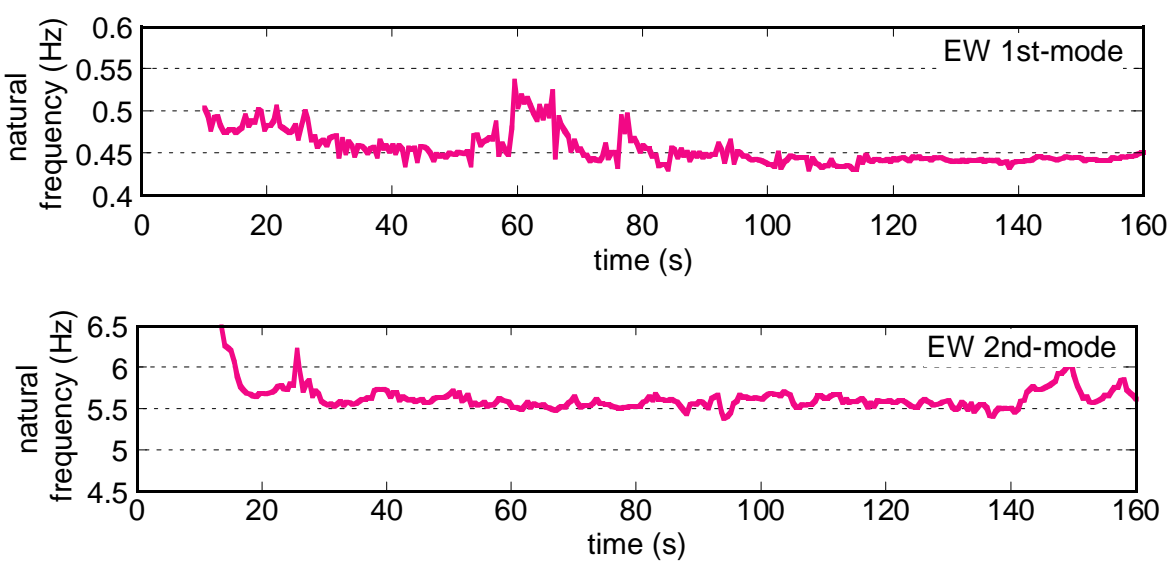

Fig.12 Temporal variation of fundamental and second natural frequencies

(Tokaido-oki Earthquake 2004.9.5 EW)
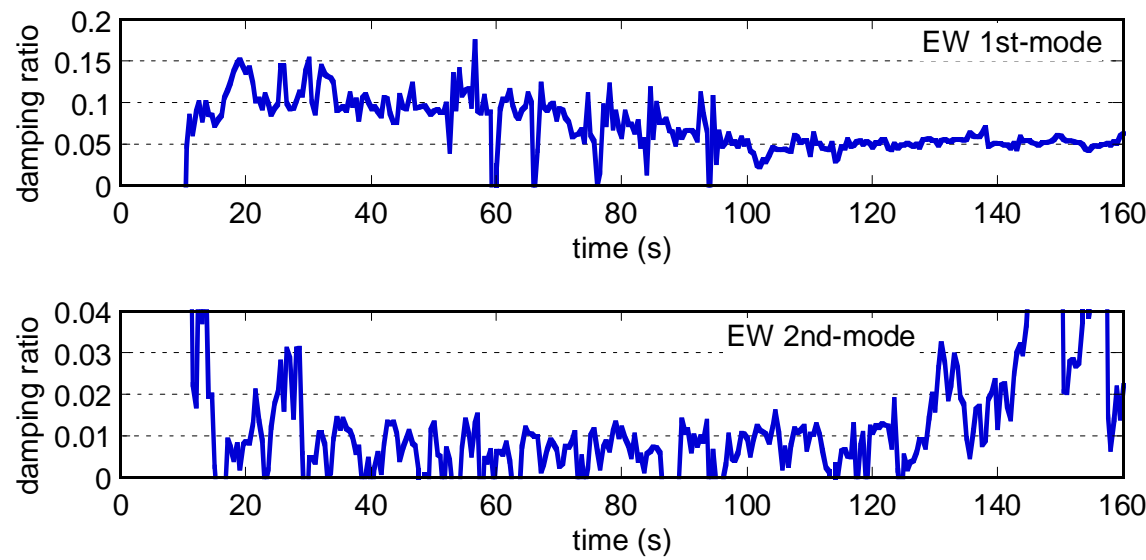

Fig.13 Temporal variation of damping ratios of fundamental and second natural modes (Tokaido-oki Earthquake 2004.9.5 EW)

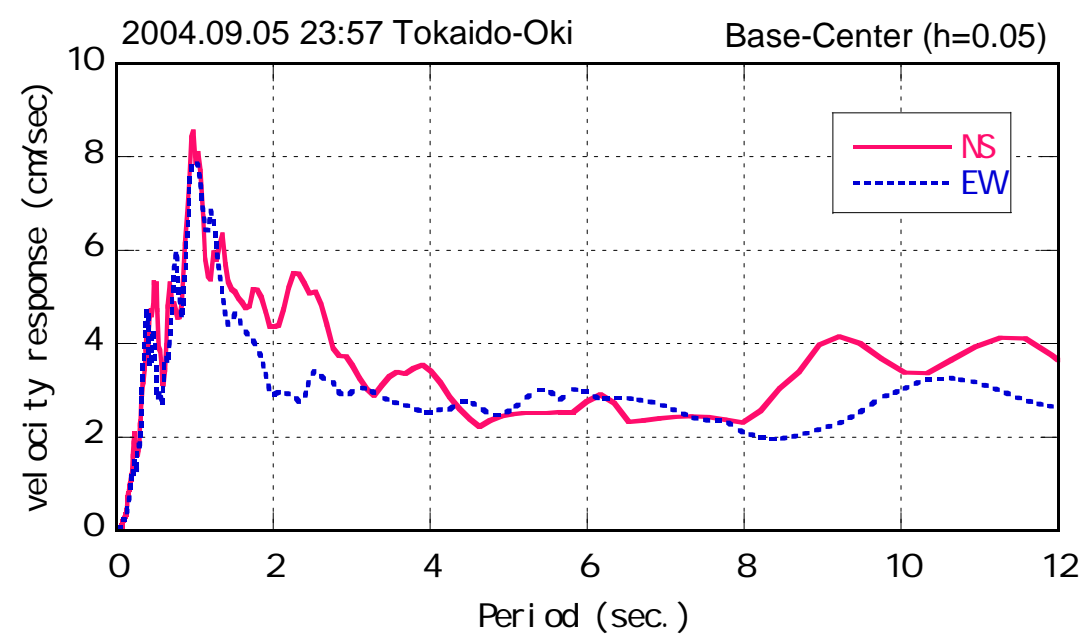

Fig.14 Velocity response spectra of Tokaido-oki Earthquake 2004.9.5 


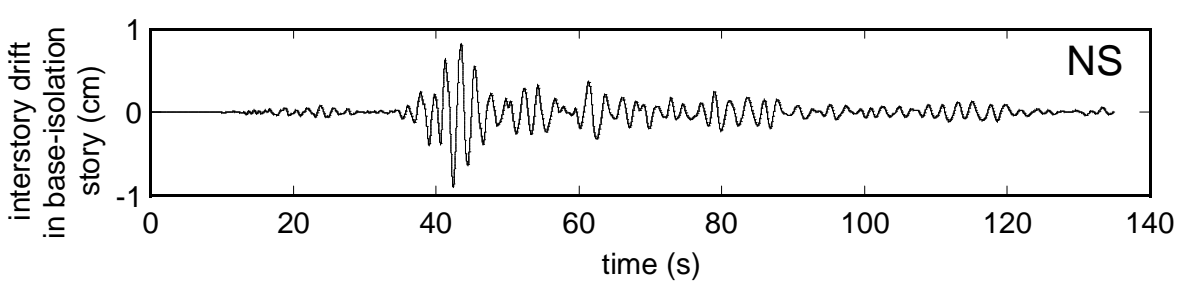

(a)

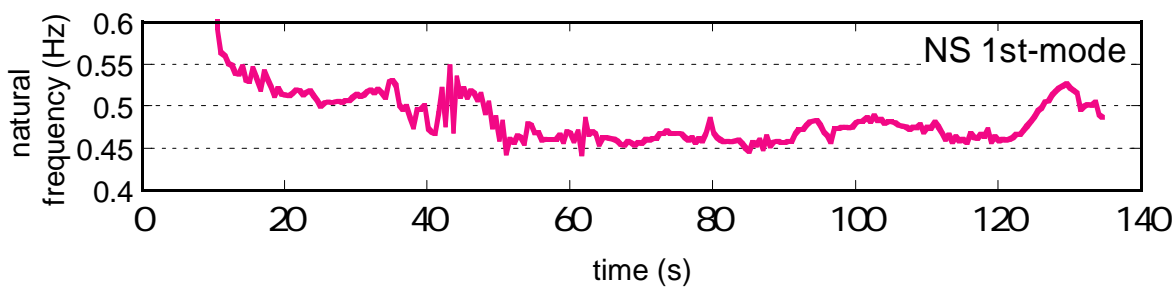

(b)

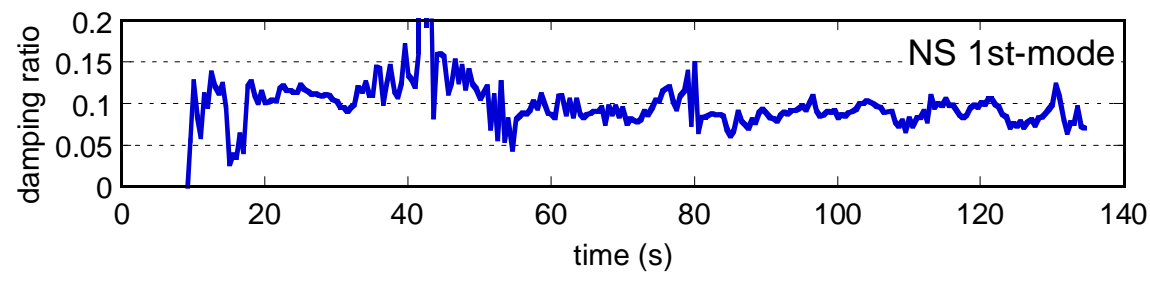

(c)

Fig.15 Tottoriken-Seibu 2000 NS, (a) interstory drift in the base-isolation story, (b) fundamental natural frequency, (c) lowest-mode damping ratio

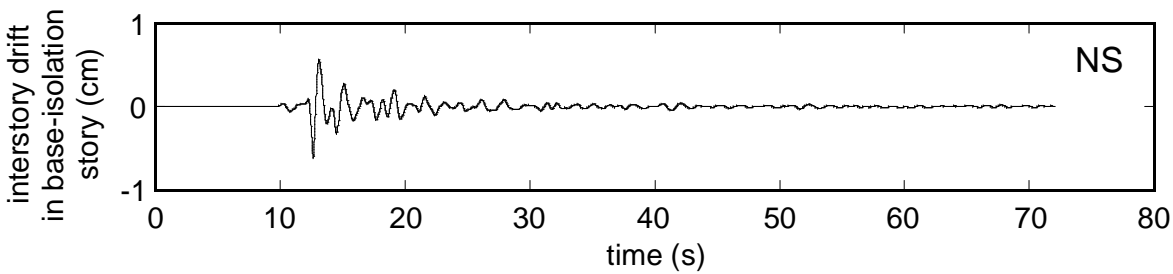

(a)

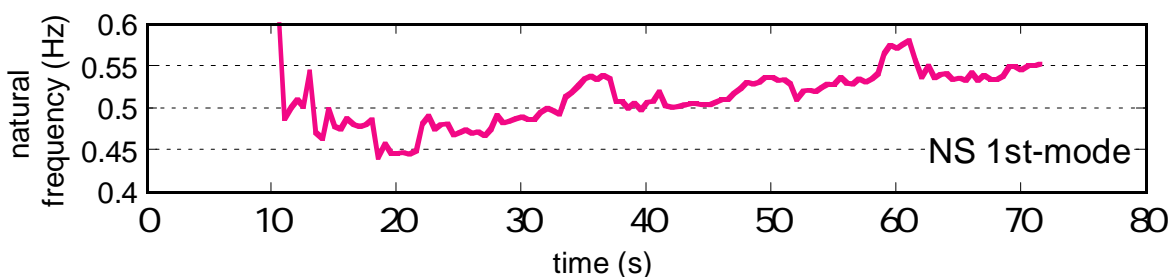

(b)

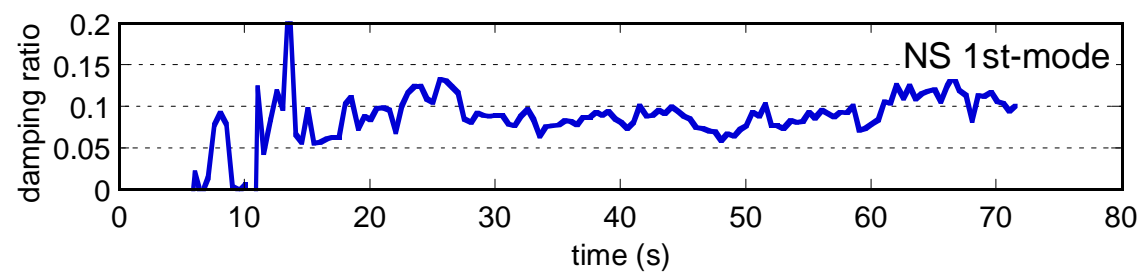

(c)

Fig.16 South of Kyoto Prefecture 2001 NS, (a) interstory drift in the base-isolation story, (b) fundamental natural frequency, (c) lowest-mode damping ratio 